\title{
Conceiving of an Electrochemical Cell for In Situ Hydrodynamic Approach
}

\author{
Pierre Jean-Marie R. Dablé*,1, Eric Chaïnet ${ }^{2}$, Benjamin Yao ${ }^{3}$ and Ado Gossan ${ }^{3}$
}

\begin{abstract}
${ }^{I}$ Institut National Polytechnique Houphouët BOIGNY de Yamoussoukro; Département de Génie Chimique et Agro-Alimentaire. Laboratoire des Procédés et Mécanique des Matériaux - BP 1093 Yamoussoukro R.C.I.

${ }^{2}$ Institut National Polytechnique de Grenoble; Laboratoire d'Electrochimie et de Physico-chimie des Matériaux et des Interfaces; unité mixte de recherche 5631; INPG/UJF - CNRS; 1130, rue de la piscine Domaine Universitaire BP 75 38402 St Martin d'Hères CEDEX, France

${ }^{3}$ Institut National Polytechnique Houphouët BOIGNY de Yamoussoukro; Département de Génie Chimique et Agro-Alimentaire. Laboratoire de Procédés Industriels de Synthèse et de l'Environnement - BP 1093 Yamoussoukro R.C.I.
\end{abstract}

\begin{abstract}
In the purpose of in situ control of hydrodynamic influence on electrochemical processes, a cell jet device has been conceived and characterized. This cell was sensitive to parameters that are the jet tube diameter, and its height versus the working electrode. So, the three hydrodynamic flow modes have been established from the non dimensional Reynolds number. From the use of this cell for the study of co deposition from the Ni/SiC system with a WATT bath, it was shown that the turbulent flow to favor more embedment of SiC particles in the nickel matrix. It also noted an influence of the flow mode and $\mathrm{SiC}$ particles on the working current.
\end{abstract}

Keywords: Flow, Hydrodynamic, Co-deposition, Ni/SiC system.

\section{INTRODUCTION}

The hydrodynamic forces play a significant role in the electrochemical processes (Levich 1962) [1]. They can support or disturb the migration of the ions towards the electrodes to carry out reactions there (Poulson 1983) [2]. These changes are due to the modification of the mass transfer coefficient which supports the electrochemical reaction. In addition, these forces control the transport of inert matter in solution (Stappers 2005) [3].

To study the impact of the hydrodynamic on the quoted systems, several types of cells were considered such as the cell with normal jet electrode (Alkire et al. 1982; Bouet 1994) $[4,5]$. This device is used since about thirty years for various industrial applications with an aim of increasing the coefficients of mass transfer.

The flow on a fixed plane surface receiving a normal fluid flush breaks up into three zones whose sizes and positions depend on the geometry of the system and the characteristics of the flow. Three zones can be distinguished; the zone of stagnation, the zone of transition and the zone of wall as depicted in Fig. (1) (Glauert et al. 1956; Yamada et al. 1973) $[6,7]$. In the zone of stagnation, the jet is deviated from its normal trajectory in a radial flow which increases linearly according to the radial position with a flow of the axis symmetric type.

*Address correspondence to this author at the Institut National Polytechnique Houphouët BOIGNY de Yamoussoukro; Département de Génie Chimique et Agro-Alimentaire. Laboratoire des Procédés et Mécanique des Matériaux - BP 1093 Yamoussoukro R.C.I;

E-mails: pjmardable@yahoo.com; dable_pierre@yahoo.fr

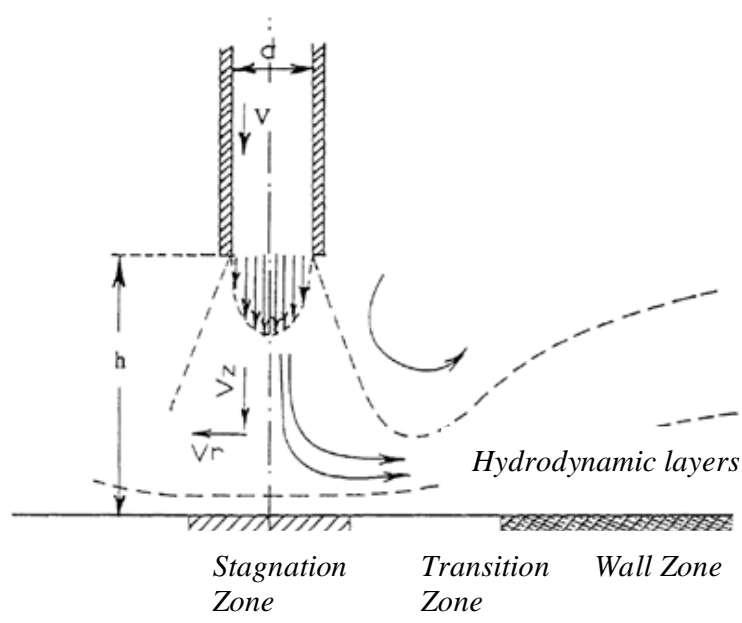

Fig. (1). Characteristic of the flow.

In hydrodynamic, three types of flows can be distinguished:

\section{The Laminar Flow}

The layers of liquid slip the ones on the others with a local speed independent of time.

\section{The Turbulent Flow}

Characterized by swirls, mix the layers of liquids. The local speed values fluctuate with time.

\section{The Transitory Flow}

Located between the streamline flow and the turbulent flow is characterized by strong instabilities. 
Many works have been undertaken to establish the hydrodynamic parameters that influence the $\mathrm{Ni} / \mathrm{SiC}$ co deposition process, (Lavanant 1991; Kaisheva et al. Nowak et al. Wang et al. Yeh et al. Dable et al.) [8-13].

This work aims to establish the influence of the hydrodynamic mode on the process of co-deposition of the $\mathrm{Ni} / \mathrm{SiC}$ system, and to characterize a normal cell with jet. To begin with, we present the hydrodynamic considerations that controlled the system, the techniques assembled for the qualification and the quantification of the results, as well as the data of tests carried out with the system of co-deposition.

\section{STUDY OF THE HYDRODYNAMIC SYSTEMS}

Hydrodynamic systems are characterized by non dimensional numbers (Coeuret and Storck 1984) [14].

The SHERWOOD number $S h$ represents the mass transfer to an electrode of radius $R$. It draws up the relationship between a characteristic dimension and the thickness of the layer of diffusion. It quantifies the importance of the transfer by convection compared to the transfer by diffusion. It represents the ratio of convective to diffusive mass transport

$S h=\frac{K \times R}{D}$

With $K$ the mass transfer coefficient, and $D$ the coefficient of diffusion of the species. If the reaction considered is electrochemically limited by the diffusion of the electro active species of concentration $C$ with a limiting current $i_{l}$, the SHERWOOD number is determined by the following relation:

$$
S h=\frac{i_{l} \times R}{\text { n.F.D.C }}
$$

With $n$, the number of exchanged electrons, $F$ the number of faraday, $D$ the coefficient of diffusion of the species and $C$ its concentration in the electrolyte.

The REYNOLDS number; $R e$ is used to characterize different flow regime. It represents the importance of the inertias forces associated to the flow compared to the forces with viscosity. For a flow in a tube where $V$ is the mean velocity of flow and $d$ the diameter of the tube $R e$ is given by the expression:

$$
R e=\frac{V \times d}{v}
$$

With $v$, the cinematic viscosity of the electrolyte. This number is used to characterize the hydrodynamic modes for a considered system. Knowing the radius of the tube in $\mathrm{cm}$ and the flow $D^{\circ}$ of the electrolyte in $\mathrm{cm}^{3} / \mathrm{sec}$, the velocity of flow of the liquid corresponds to the height of liquid moved by a second:

$V=\frac{D^{\circ}}{\pi \cdot R^{2}}$

The SCHMIDT number; $S c$ is a dimensionless number defined as the ratio of momentum diffusivity ( $v$ cinematic viscosity) and diffusivity $(D)$, and is used to characterize fluid flows in which there are simultaneous momentum and mass diffusion convection processes:
$S c=\frac{v}{D}$

The GRASHOF number; noted $G r$ is a dimensionless number in fluid dynamics and Heat Transfer which approximates the ratio of the buoyancy to viscous force acting on a fluid. It intervenes only in natural convection.

The mass transfer by diffusion - convection is represented (when the free convection is associated to the convection forced) by the correlation of these four non dimensional numbers:

$$
S h=a \cdot \operatorname{Re}^{d} \cdot G r^{c} \cdot S c^{d}
$$

With $a$, the hydrodynamic constant, which characterizes the flow mode. In forced convection, the number $\mathrm{Gr}$ has a negligible influence. Relation becomes:

$S h=a \cdot R e^{b} \cdot S c^{d}$

The works undertaken in the zone of stagnation establish that the number of SHERWOOD; $S h$ varies in $R e^{1 / 2}$ and $d$ is equal to $1 / 3$ for laminar flow.

$S h=a \cdot \operatorname{Re}^{\frac{1}{2}} \cdot S c^{\frac{1}{3}}$

\section{DESIGN OF THE ELECTROCHEMICAL CELL}

The cell with jet depicted in Fig. (2) is constituted of three parts made out of Plexiglas:

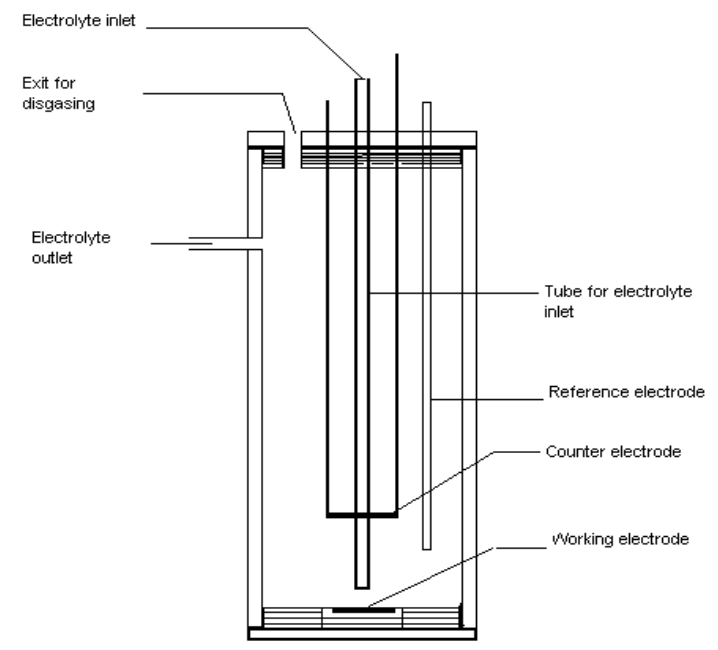

Fig. (2). Jet cell assembly.

The body is a cylinder of $15 \mathrm{~cm}$ length, with an external diameter of $8 \mathrm{~cm}$ and an internal one of $7 \mathrm{~cm}$. The two ends are machined in threading inside on $1 \mathrm{~cm}$ length, with a thickness of $2 \mathrm{~mm}$. This was done in order to screw the two other parts in it. At $4 \mathrm{~cm}$ from one of the extremities, a tube of $6 \mathrm{~mm}$ of diameter is perpendicularly positioned in order to release the electrolyte excess.

The upper side is the higher part which holds the tubes for the introduction of the reference electrode, the counter electrode and to ensure the degasification of the electrolyte. It consists of a plate with $1.5 \mathrm{~cm}$ 
thickness and an external diameter of $8 \mathrm{~cm}$. For joining the body, the diameter of the plate is reduced in $3 \mathrm{~mm}$ over a length of $1 \mathrm{~cm}$, and with a $2 \mathrm{~mm}$ thread.

A perforation of $23 \mathrm{~mm}$ diameter is made in the centre of the plate in order to fix tubes' holders.

The lower side: The support of the working electrode is also a circular plate of $8 \mathrm{~cm}$ of external diameter. Like the upper side, for joining the body, the external diameter is a tiny room of $3 \mathrm{~mm}$ and with a $2 \mathrm{~mm}$ thread on a height of $8 \mathrm{~mm}$. A notch of $3 \mathrm{~mm}$ allows the introduction of a joint to ensure the sealing of the cell. To hold the working electrode, which consists of a device of electrode with quartz, the centre of the part is machined for the installation of this device with a good sealing.

After assembly, the cell offers a useful volume of 115 $\mathrm{cm}^{3}$. To ensure the operation of the cell, a pump provides the circulation of the electrolyte via the tube of cell. This electrolyte exists in the form of jet at the surface of the working electrode and is evacuated on being too full. Thus, the electrolyte circulates in the cell by means of the jet on the surface of the working electrode.

The hydrodynamic parameters that vary are: the flow of the electrolyte, the Reynolds number that is related to the diameter of the tube, and the height between the bottom of the tube and the working electrode.

\section{CHARACTERIZATION OF THE CELL}

The characterization of the cell consists of the determination of the conditions which delimit the various flow modes of the electrolyte. The study was done with an equimolar solution of hexacyanoferrate III and II of potassium. The kinematics viscosity of this solution determined by the method of Schott led to the value of $1 \mathrm{~mm}^{2} / \mathrm{sec}$. The circulating pump of the electrolyte calibrated prior to use.

The reactions awaited in this solution are the reduction of the $\mathrm{Fe}^{3+}$ ions into $\mathrm{Fe}^{2+}$ and in return, the oxidation of the $\mathrm{Fe}^{2+}$ into $\mathrm{Fe}^{3+}$. In this purpose, an electrode of gold is used as anode. The parameters taken into account for flow characterization were the tube section, its height from the working electrode surface, the flow of the electrolyte used for the calculation of the flow velocity, and the electrolyte cinematic viscosity. These data allowed calculation of the Reynolds number from relation 3 .

For given parameters, a tension of $-0.7 \mathrm{~V}$ was applied to the cell and the oxidation and reduction current were recorded. From relations 2 and 8, the following relations between the limiting diffusion current and the square root of the Reynolds number were established:

$i l=\frac{a \times n \times F \times C \times D \times S c^{1 / 3}}{R} \mathrm{Re}^{1 / 2}$

That is to say:

$i l=\alpha \times \operatorname{Re}^{1 / 2}$

Therefore for the cell characterization, the measurement of $i l$ for any Reynolds number was performed. Consequently, from the representation of $i l$ versus $R e^{1 / 2}$, the hydrodynamic type that occurred was defined.

\section{EXPERIMENTAL RESULTS}

\section{Analyses and Interpretations}

The representations obtained from the experimental data give lines which delimit characteristic fields of the flows that take place. According to relation 9, the slops represent the value of $\alpha$. By the way the parameters $n, F, C, D$ and the SCHMIDT number are fixed for each experimentation, $\alpha$ stays proportional to $a$, that characterizes the flow regime. Therefore any slop changing corresponds to a change of flow regime.

It clearly appears from the experimental figures that the cell highlights the flow changes. For the Reynolds number field swept, different slops characterizing change in the flow mode can be distinguish. Anyway for the same flow, variation according to the experimental parameters are found. This also pulls out that the cell is sensitive to experimental conditions.

\section{INFLUENCE OF THE ELECTROCHEMICAL PROCESS AND THE HEIGHT}

For the experimental conditions of the Figs. (3a and $\mathbf{3 b}$ ) that respectively correspond to oxidation and reduction reactions, the three fields of flow modes are perfectly defined. For both processes, laminar flow stands until $R e$ value around 144; then the flow becomes transitory until $R e$ value of 290. The turbulent flow starts for higher Reynolds numbers.

$\mathbf{a}$

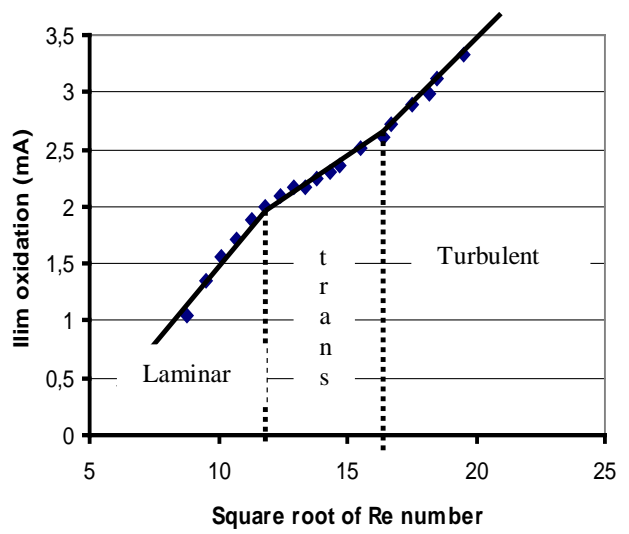

b

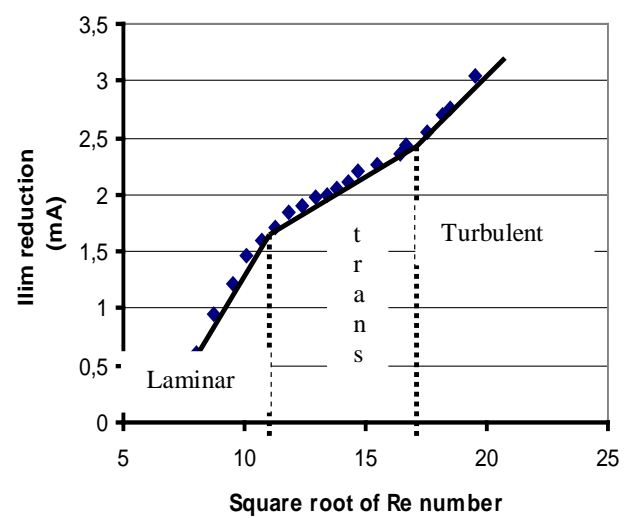

Fig. (3). a. Oxidation limit current versus $\operatorname{Re}^{1 / 2}$; for $\Phi=5 \mathrm{~mm}$; $\mathrm{H}=5 \mathrm{~mm}$. b. Reduction limit current versus $\mathrm{Re}^{1 / 2}$; for $\Phi=5 \mathrm{~mm}$; $\mathrm{H}=5 \mathrm{~mm}$. 
For internal flow studies, laminar flow persists until Reynolds numbers closed to 2300 and turbulent flow appears for higher values. Nevertheless, in the case of this study, the values of Reynolds number corresponding to the change of the flow modes are lower than the values theoretically established by the hydrodynamic studies. In connection with the expression of the Reynolds number (relation 3), this is the consequence of the rate value of the flow considered here. Indeed, the fluid flush that arrives at the surface of the working electrode undergoes a disturbance by the layers in convection after they ran up against the zone of wall. The local speed so increases and this should lead to higher Reynolds numbers.

For the other experimental conditions only laminar and turbulent flows appear. However, according to the electrochemical reactions that occur, either oxidation or reduction, one can notice a variation of the limit current values. This also points out a real influence of the flow mode on the electrochemical species transfer to the working electrode. Obviously, these variations are to be linked to experimental parameters that are the jet tube section and its height.
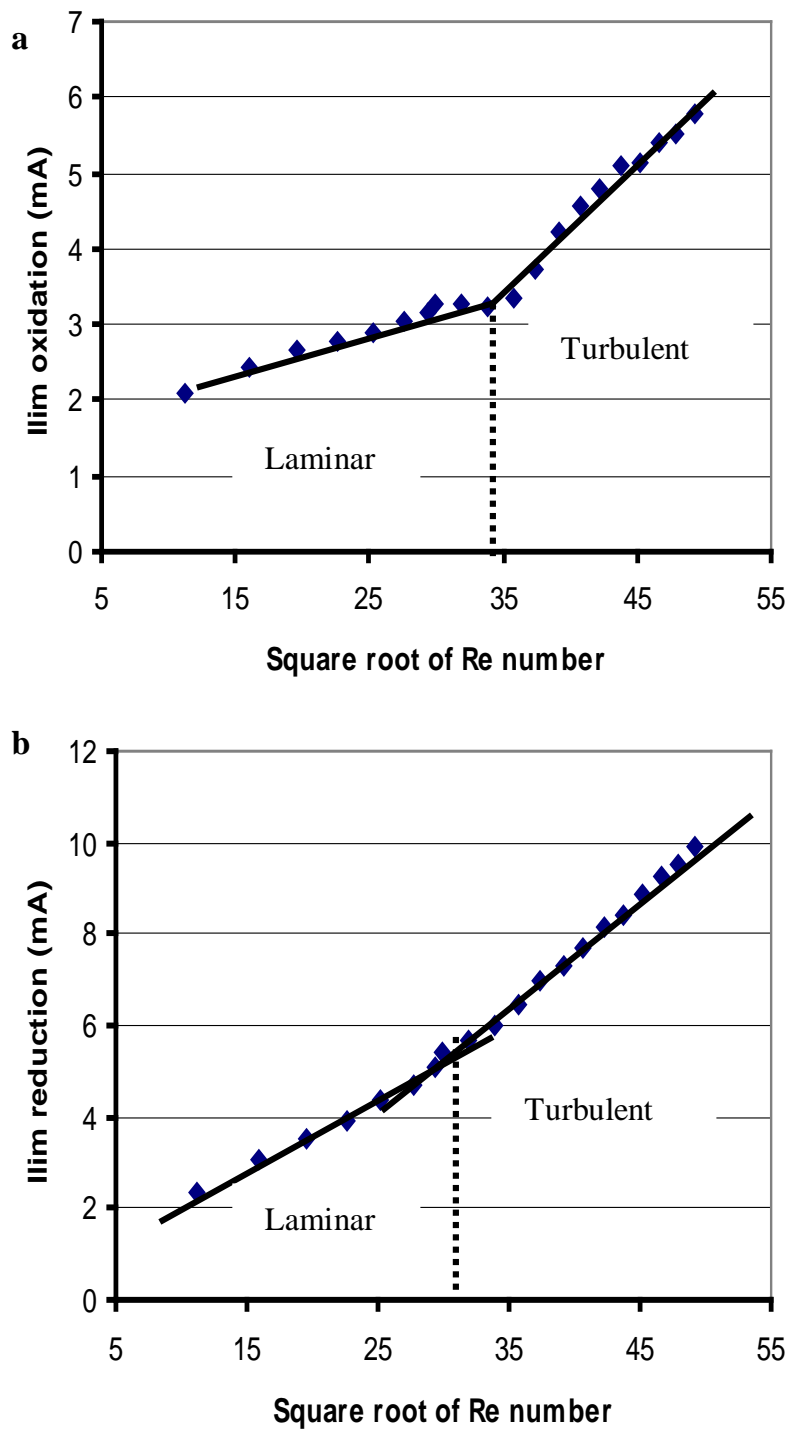

Fig. (4). a. Oxidation limit current versus $\operatorname{Re}^{1 / 2}$ for $\Phi=5 \mathrm{~mm}$; $\mathrm{H}=1 \mathrm{~cm}$. b. Reduction limit current versus $\mathrm{Re}^{1 / 2}$; for $\Phi=5 \mathrm{~mm} ; \mathrm{H}=$ $1 \mathrm{~cm}$.
From Figs. (3b and $\mathbf{4 b}$ ), for the same electrochemical process, with the same jet section and a height $\mathrm{H}$ twice higher, a transitory flow appears for the smaller height value and does not appears when the height is twice higher.

As the Reynolds numbers are proportional to the flow speed, this pulls out that when the height is small; the flow undergoes instability with increasing flow speed while, this is not the case for higher height. Considering the dimensions, the mass of the liquid flushing the working electrode is twice higher and presents more inertia so that it stays stable toward the whirls coming from the wall zone. When the height is smaller, the mass of liquid presents less inertia and it is so easily disturbed that it induces an apparition of transitory flow.

\section{INFLUENCE OF THE TUBE SECTION $\Phi$}

Comparing Figs. (4 and 5) with tube section ranging from $0.785 \mathrm{~cm}^{2}$ to $2 \mathrm{~cm}^{2}$ for the same height of $1 \mathrm{~cm}$, transitory flow doesn't appear. Therefore, the mass of liquid in both cases presents more inertia and stays stable toward the whirls for Reynolds numbers ranging from 144 to 290 as noted primarily.

a

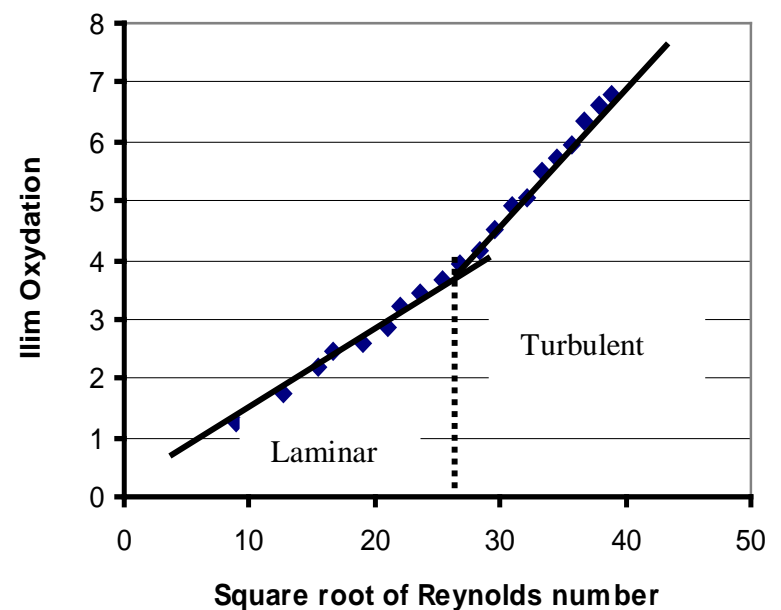

b

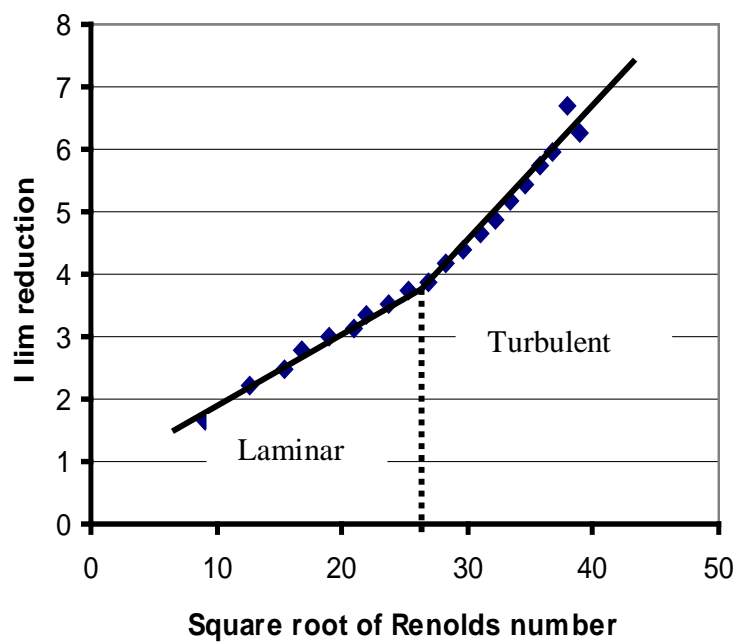

Fig. (5). a. Oxidation limit current versus $\mathrm{Re}^{1 / 2}$; for $\Phi=8 \mathrm{~mm}$; $H=$ $1 \mathrm{~cm}$. b. Reduction limit current versus $\operatorname{Re}^{1 / 2}$; for $\Phi=8 \mathrm{~mm} ; \mathrm{H}=1 \mathrm{~cm}$.

For the same composition, the mass of liquid stays proportional to the volume. Therefore, the volumes of liquid 
flushing the working electrode are respectively $0.785 \mathrm{~cm}^{3}$ and $2 \mathrm{~cm}^{3}$ whereas for Figs. (3) with transitory flow this volume is only of $0.39 \mathrm{~cm}^{3}$. This last value is feeble as compared to both mentioned first. The mass of liquid presents less inertia and is therefore subject to instabilities, leading to the emergence of transitory flow.

Moreover, for the same experimental conditions, for different electrochemical processes, the change of flow occurs for the same Reynolds number which is around 1100 and 700. These values are inversely proportional to the evolution of the section. The change in the flow regime occurs for inferior flow speed when the section is wider.

The flow regime is controlled by the fluid lines of flow in the tube. If the local speed of flow increases, these lines undergo destabilization, inducing the change of the flow mode from laminar to turbulent. Thus, for wider section, when more liquid is expulsed, local speed increases.

Taking into account the conclusions done for the height change and section variation, the local speed should be relied to the experimental one by an exponential function of the form:

$$
L_{\text {speed }}=E_{\text {speed }} \times \exp (k \phi)
$$

With $L_{\text {speed }}$ and $E_{\text {speed }}$ respectively, the local and experimental speeds, $K$ a constant and $\phi$ the flow section.

Considering current values; one can notice that the local speeds are relatively high for a higher height and a larger section. This indicates that more chemical species are in contact with the electrode and are able to be oxidized or reduced for the same duration so that the current becomes higher. For the same time, as more liquid is expulsed, the local speed also increases and consequently, Reynolds number increases. As a results, current values vary with the Reynolds numbers as expressed by relation 10 .

The experimental results correctly translate a great sensitivity and stability of the device. Flow modes are determined from Reynolds numbers and the respective ranges are very well established. This allows the use of the device for in situ hydrodynamic approach. Oxidation and reduction processes for a given system are influenced in the same manner by the flow mode when they are concomitant. Considering the reaction of oxidation and reduction that takes place, the parameter $a$, that characterizes the laminar flow of the device can be determined from the expression of

$\alpha:=\frac{\alpha \times R}{n \times F \times C \times D \times S c^{1 / 3}}$

With Sc=1136; $\mathrm{C}=5.10^{-3} \mathrm{~mol} / \mathrm{l} ; \mathrm{n}=1$;

$\mathrm{D}=8.8210^{-2} \mathrm{~cm}^{2} / \mathrm{sec} ; \mathrm{F}=96500 \mathrm{coul} ; \mathrm{R}=0.25 \mathrm{~cm}$.

The values calculated are: $a_{o x}=2.4110^{-4}$ and

$\mathrm{a}_{\text {red }}=2.23510^{-4}$.

\section{APPLICATION TO CODEPOSITION BY NICKEL REDUCTION FROM NI/ SIC SYSTEM}

The cell with jet is used to follow the reduction of nickel ions present in a solution of WATT with the following composition:
$\mathrm{NiCl}_{2} ; 6 \mathrm{H}_{2} \mathrm{O}$
$140 \mathrm{~g} / \mathrm{L}$
$\mathrm{NiSO}_{4} ; 7 \mathrm{H}_{2} \mathrm{O}$
$170 \mathrm{~g} / \mathrm{L}$
$\mathrm{H}_{3} \mathrm{BO}_{4}$
$40 \mathrm{~g} / \mathrm{L}$
$\mathrm{SiC}$
$30 \mathrm{~g} / \mathrm{L}$

The kinematics viscosity of this electrolyte established by the method of Schott led to the value of $1.6710^{-2} \mathrm{~cm}^{2} / \mathrm{sec}$. The reference electrode out of sintered glass is constituted of a solution containing the same numbers of moles in ions $\mathrm{Cl}^{-}$ and $\mathrm{SO}_{4}{ }^{2-}$. This solution is produced with the following components and proportions:

$\begin{array}{ll}\mathrm{NaCl} & 69 \mathrm{~g} / \mathrm{L} \\ \mathrm{Na}_{2} \mathrm{SO}_{4} & 195 \mathrm{~g} / \mathrm{L} \\ \mathrm{H}_{3} \mathrm{BO}_{3} & 40 \mathrm{~g} / \mathrm{L}\end{array}$

The working electrode is a quartz plate of $0.2 \mathrm{~mm}$ thickness with a metal finished surface of $1.35 \mathrm{~cm}^{2}$ centred at its middle. The counter electrode is a pure nickel grid laid out so that it is crossed by the tube. It is fixed at $6 \mathrm{~cm}$ starting from the working electrode so that the exit of the electrolyte is done apart from the zone of the lines of fields. The quartz plate has a fixed frequency of vibration. In this work, quartz of $5 \mathrm{MHZ}$ frequency is used. In the study device, the electrode of quartz is connected in cathode to receive the nickel ion. It is also connected with a microbalance which records in percentage; the variation of quartz vibration frequencies (Gabrielli et al. 1991) [15]. The variation of this frequency is converted into mass variation by:

$$
\Delta f=\frac{-2 f_{0}^{2}}{s \times \sqrt{\mu \rho}} \times \Delta m=-K . \Delta m
$$

With $S$ the deposit surface, $\rho$ the quartz volume weight; $\mu$ the cutting module; $f_{0}$ the quartz intrinsic frequency of vibration. For a given applied tension, the reaction duration is fixed and the frequency variation is measured to determine the $\Delta m$ value.

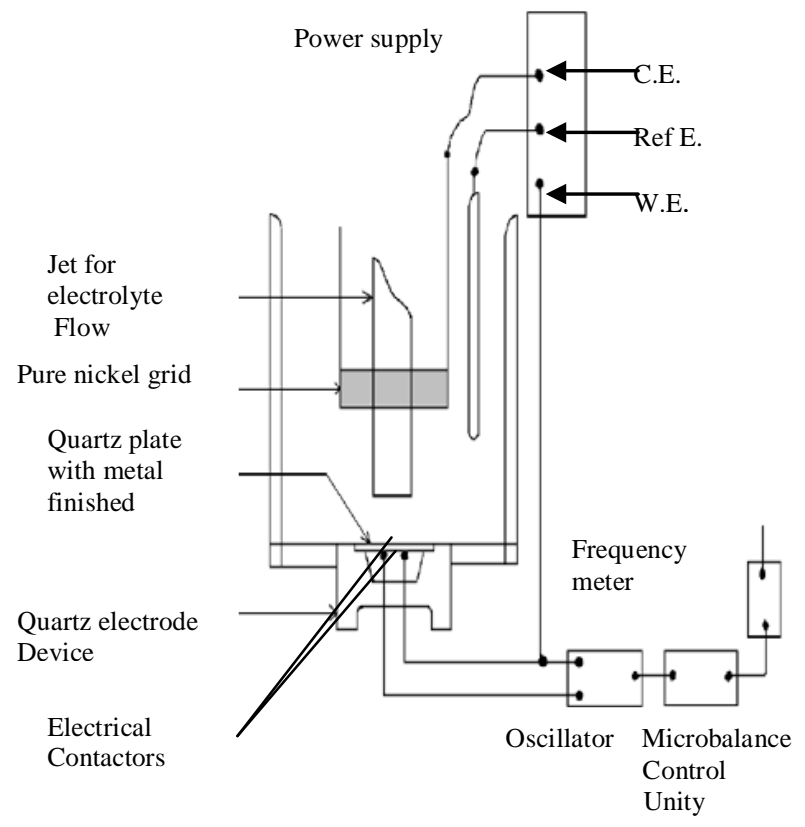

Fig. (6). Experimental device for $\mathrm{Ni} / \mathrm{SiC}$ co-deposition.

Thus the study will make it possible to establish the influence of the various types of flows on the variation of mass 
of the electrode by reduction of the nickel ions and $\mathrm{SiC}$ particles embedded. Therefore, for a given reduction tension fixed to $-0.9 \mathrm{~V}$, nickel ions are reduced from a bath without particles to another one containing $30 \mathrm{~g} / \mathrm{L}$ of $\mathrm{SiC}$ particles.

According to relation 13, and as shown by Fig. (7), the ratio between the frequencies variation from bath without particles and the one containing particles, indicates the increase of mass due to particles. Thus, the study will make it possible to establish the influence of the various types of flows on the catch of mass of the electrode by reduction of the ions nickel and $\mathrm{SiC}$ particles embedded. Therefore, for a given reduction tension fixed to $-0.9 \mathrm{~V}$, nickel ions are reduced from particles free bath and with another one containing $30 \mathrm{~g} / \mathrm{L}$ of $\mathrm{SiC}$ particles.

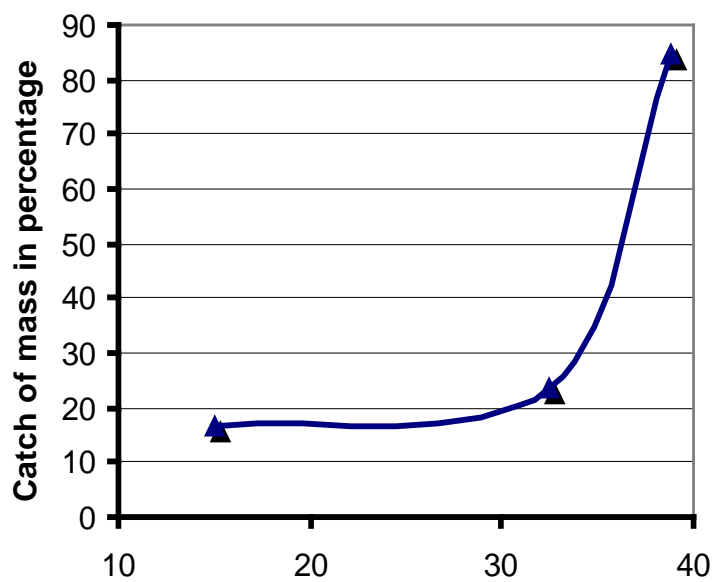

Square root of Reynold number

Fig. (7). Catch of mass as a function of $\mathrm{Re}^{1 / 2}$

According to relation 13, the ratio between the frequencies variation from particles free bath indicates the catch of mass due to particles; Fig. (7). It clearly appears that turbulent low favors $\mathrm{SiC}$ particles embedment. In these conditions, around $85 \%$ of the catch of mass corresponds to $\mathrm{SiC}$ particles embedded. This is also confirmed by Figs. (8) and (9) that respectively correspond to sample elaborated under streamline flow and turbulent flow. The sample elaborated under turbulent flow clearly presents more embedded particles.

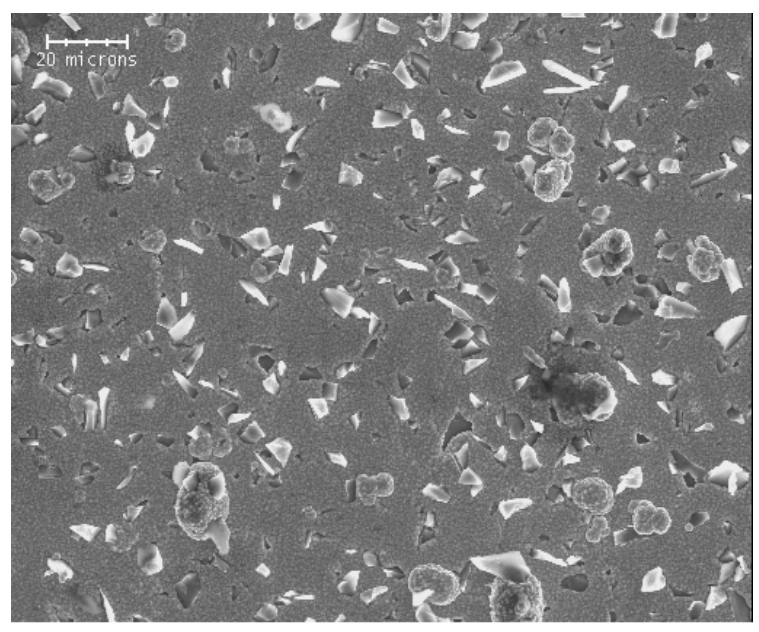

Tension of reduction $-0.9 \mathrm{~V}$, deposition duration $180 \mathrm{sec}$, Reynold nurnber 225

Fig. (8). Sample of deposition under streamline flow.

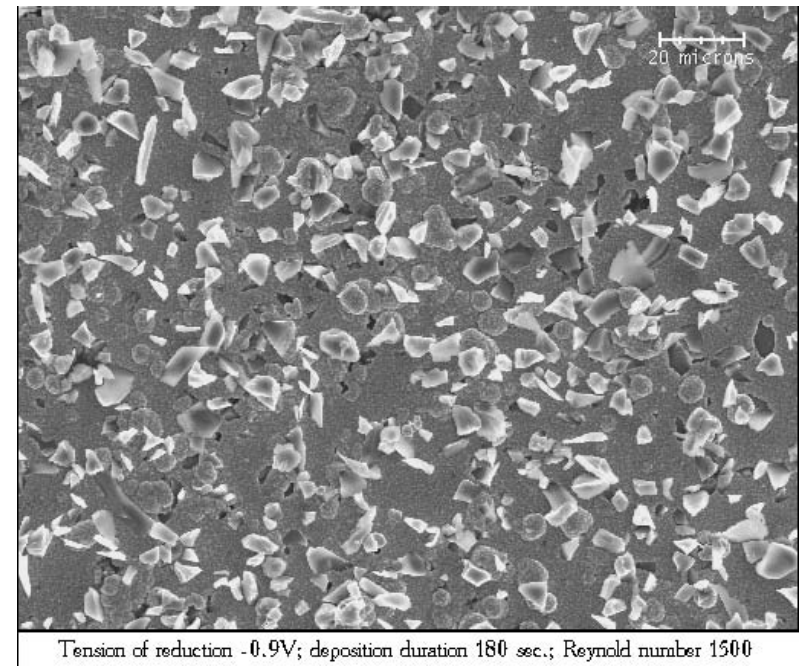

Fig. (9). Sample of deposition under turbulent flow.

The flow mode also induces variation of the reduction current intensity. This becomes higher with increasing Reynolds number that characterizes an augmentation of the flow speed. Therefore, more active species are transported to the electrode surface increasing which charge quantity, inducing consequently a higher current. On another hand, presence of $\mathrm{SiC}$ particles in the electrolyte enhance current variation that becomes higher. This observation supports adsorption of nickel ions on $\mathrm{SiC}$ particles that are transported by the flow to the electrode, increasing thus reduction current.

\section{CONCLUSION}

The cell with jet thus conceived has a clear stability for the modes of laminar flow and turbulent with values of practically constant Reynolds numbers. It answers quite well to the variations of the parameters which are: the height of the jet and the diameter of the tube. It thus allows with much ease the in situ study of the hydrodynamic behavior of a fluid.

The process including the cell with jet, also highlights, a variation of the currents of reduction in the presence of the silicon carbide particles in the electrolyte. This makes it possible to carry out with ease the faradic aspects of the codeposition process. Thus the cell with jet characterized should allow a simultaneous study of the hydrodynamics and electrochemistry.

\section{REFERENCES}

[1] V.G. Levich, Physicochem. Hydrodynamics, Prentice Hall, 1962.

[2] B. Poulson, "Electrochemical measurements in flowing solutions", Corrosion Sci., vol. 24, no. 4, pp. 391- 401, 1983.

[3] L. Stappers, and J. Fransaer, "The effect of turbulence on the electrodeposition of composite coatings", J. Electrochem. Soc., vol. 152, no. 6, pp. C392 -C398, 2005.

[4] T. Alkire, and J. Chen, "Micro fabrication by electrochemical metal removal”, J. Electrochem. Soc., vol. 129, pp. 2424-2434,1982.

[5] Bouet Véronique; Interaction Particules Isolantes/ Electrode : Mise en Euvre de Méthodes Electrochimiques. Application aux Revêtements Composite Electrolytiques; Thèse de Doctorat Paris 6, 1994.

[6] M.B. Glauert, "The wall jet", J. Fluid Mech., vol. 1, pp. 625-635, 1956.

[7] J. Yamada, and H. Matsuda, Electroanal. Chem., vol. 44, pp. 189 $195,1973$. 
[8] A. Lavanant, Electrodeposition of Ni/ Silicon Carbide Composite Coatings; Thèse de Doctorat, Paris 6, 1991.

[9] M. Kaisheva, and J. Fransear, "Influence of the Surface properties of $\mathrm{SiC}$ particles on their Codeposition with Nickel", J. Electrochem. Soc., vol. 151, no. 1, pp. C89-C96, 2004.

[10] P. Nowak, R.P. Socha, M. Kaisheva, and J. Fransaer, "Electrochemical Investigation of the Codeposition of $\mathrm{SiC}$ and $\mathrm{SiO} 2$ Particles with Nickel", J. Appl. Electrochem., vol. 30, pp. 429-431, 2000 .

[11] S.W. Wang, and J. Wen-Cheng, "Electrokinetic properties of nanosized SiC particles in highly concentrated electrolyte solutions", J. Am. Ceram. Soc., vol. 84, pp. 1411-1414, 2001.
[12] S.H. Yeh, and C.C. Wan, "Codeposition of SiC Particles with Nickel in a WATT's Bath", J. Appl. Electrochem., vol. 24, no. 10, pp. 993-1000. 1994.

[13] P.J.M.R. Dablé, E. Chaïnet, B. Yao, "Chemical Evolution of SiC Particles Surface in Salt Solution", J. Applied Sc., vol. 7, no. 6, pp: 861-861, 2007.

[14] F. Coeuret, A. Storck, "Eléments de Génie Electrochimique". Edited by TEC \& DOC Lavoisier, 1994.

[15] C. Gabrielli, M. Keddam, and R. Torresi, "Calibration of the Electrochemical Quartz Microbalance", J. Electrochem. Soc., vol. 138 , pp. 2657-2667, 1991.

Received: August 01, 2008

(C) Dablé et al.; Licensee Bentham Open.

This is an open access article licensed under the terms of the Creative Commons Attribution Non-Commercial License (http://creativecommons.org/licenses/by-nc/3.0/) which permits unrestricted, non-commercial use, distribution and reproduction in any medium, provided the work is properly cited. 